The Review of Higher Education

Summer 2006, Volume 29, No. 4, pp. 425-450

Copyright (C) 2006 Association for the Study of Higher Education

All Rights Reserved (ISSN 0162-5748)

\title{
Relationships among Structural Diversity, Informal Peer Interactions and Perceptions of the Campus Environment
}

\author{
Gary R. Pike and George D. Kuh
}

Almost half of the U.S. population will be racial/ethnic minorities by the year 2030 (Cortes, 1991). Colleges and universities are also becoming increasingly diverse and students of color are expected to comprise nearly two fifths of total undergraduate enrollment by 2015 (Carnevale \& Fry, 2000). In several states, minority students already make up at least one third of the student body. For example, fall 2002 minority enrollments in the four most populous states-California, Texas, Florida, and New York-were 51\%, 41\%,37\%, and 32\%, respectively (Chronicle of Higher Education, 2005).

Faced with this dramatic demographic shift, leaders in the public and private sectors have called on colleges and universities to prepare students to function effectively in a diverse society (Association of American Colleges and Universities, 1995; Bikson \& Law, 1994). Similar calls have come from within the academy by leaders such as Bowen and Bok (1998) and

GARY R. PIKE is Director of Institutional Research at Mississippi State University. GEORGE D. KUH in Chancellor's Professor and Director of the Center for Postsecondary Resarch at Indiana University Bloomington. Address queries to Gary R. Pike, Director, Office of Institutional Research, Mississippi State University, 269-A Allen Hall, P.O. Box EY, Mississippi State, MS 39762-5708; telephone: (662) 325-7445; fax: (662) 325-3514; email: gpike@ir.msstate.edu. 
Knefelkamp (1998), who assert that this challenge is now a core mission of higher education.

Ironically, the increased diversity of college campuses is partly a result of efforts to improve students' abilities related to functioning in a diverse society (Palmer, 2001; Rudenstine, 2001). Many higher education scholars argue that increased minority enrollment provides colleges and universities with an opportunity to address issues of prejudice and discrimination and better prepare students for life after college when they live and work in a diverse society (Chang, 2000, 2002; Hurtado, Dey, Gurin, \& Gurin, 2003; Smith et al., 1997). These scholars point to research indicating that a diverse college campus provides students with opportunities to interact with peers who are different from themselves and that these interactions ultimately contribute to a supportive campus environment and mediate students' intellectual and personal development (Gurin, 1999; Hurtado, Milem, Clayton-Pedersen, \& Allen, 1998, 1999). That a diverse college campus contributes to positive educational outcomes was a key argument in Justice Powell's opinion in Regents of the University of California v. Bakke (1978) which supported the use of affirmative action in college admission decisions.

The claim that a diverse student body is linked to positive educational outcomes is not universally accepted. Some critics of affirmative action policies, such as the National Association of Scholars, contend that diversity does not necessarily lead to a free exchange of ideas and positive diversity outcomes (Wood \& Sherman, 2001). Bloom (1987) and D'Souza (1991) warn that diversity initiatives may harm rather than improve relations among different racial and ethnic groups.

This study is designed to examine the relationships among the diversity of the student body (i.e., structural diversity), interactions among diverse groups of students (i.e., informal interactional diversity), and perceptions of the campus environment. Using data from a nationally representative sample of institutions, the study helps to answer questions raised by critics of diversity initiatives and illuminate what appear to be contradictory findings from different research studies. As a result, the findings add to our understanding of the value of admission policies that are intended to increase diversity on college campuses.

\section{BACKGROUND}

Much of the theory and research related to diversity experiences has focused on three features of the teaching and learning environment: (a) structural diversity, (b) classroom diversity, and (c) informal interactional diversity (Gurin, 1999; Hurtado, Dey, Gurin, \& Gurin, 2003). Structural diversity essentially represents the extent to which students of 
color are included in the student population. Classroom diversity refers to the incorporation of information about diverse groups in the curriculum. Informal interactional diversity refers to the extent to which diverse groups of faculty and students interact with one another in and out of class.

Many of the current efforts to improve diversity outcomes have focused on structural diversity, a view endorsed by Justice Powell in Regents of the University of California v. Bakke (1978). Noting that quotas, or "set asides," in admissions could not be justified, Justice Powell argued that it is permissible to use race/ethnicity as one factor in admission decisions if racial/ethnic diversity can be shown to improve the quality of the educational experience. He based his opinion on the Court's longstanding support for academic freedom, which Justice Frankfurter outlined in Sweezy v. New Hampshire (1957):

It is the business of a university to provide that atmosphere which is most conducive to speculation, experiment and creation. It is an atmosphere where there prevail "the four essential freedoms" of a university-to determine for itself on academic grounds who may teach, what may be taught, how it shall be taught, and who may be admitted to study. (p. 263)

As a result, affirmative action policies became a key lever for diversifying campuses, with institutions investing significant resources in recruiting and retaining students of color ( $\mathrm{Hu} \&$ Kuh, 2003; Pascarella, Palmer, Moye, \& Pierson, 2001; Rudenstine, 2001). Recruiting minority students is particularly significant because many scholars agree with Justice Powell that a diverse student body is a necessary condition for interactions among diverse groups. These interactions, in turn, create opportunities for students to develop skills and competencies needed to function effectively in a diverse society (Chang, 2001; Gurin, 1999; Hurtado, Dey, Gurin, \& Gurin, 2003; Hurtado, Milem, Clayton-Pedersen, \& Allen, 1998, 1999). Thus, structural diversity is thought to exert an indirect effect on student learning, acting through interactions with peers.

The preponderance of evidence generally indicates that structural diversity is positively related to informal interactional diversity. That is, students attending institutions with diverse populations report interacting more frequently with diverse peers than do students attending institutions that are relatively homogeneous (Chang, 1999; Chang, Astin, \& Kim, 2004; Gurin, 1999; Hurtado \& Wathington Cade, 1999; Loo \& Rolison, 1986). The likelihood of interacting with diverse peers is also influenced by student characteristics (e.g., being a member of a minority group, parental education, academic preparation, precollege experiences with diversity, and major field of study) and institutional characteristics (e.g., Carnegie classification, control, location, selectivity, and size) (Chang, 2001; Hu \& Kuh, 2003). 
Informal interactions with diverse peers, in turn, have a variety of positive effects on students, including enhanced intellectual development (Antonio, 2001; Gurin, 1999; Hu \& Kuh, 2003; Pascarella, Palmer, et al., 2001; Terenzini et al., 2001; Umbach \& Kuh, in press), gains in personal development (Antonio, 2001; Chang, 1999; Hu \& Kuh, 2003; Umbach \& Kuh, in press), and greater openness to diversity (Adams, 1995; Astin, 1993; Flowers \& Pascarella, 1999; Globetti et al., 1993; Henderson-King \& Kaleta, 2000; Hurtado, 1992; Pascarella, Edison, et al., 1996; Pike, 2002; Taylor, 1998; Whitt et al., 2001). In addition, informal interactional diversity appears to contribute to positive perceptions of the campus environment (Chang, 1999; Gurin, 1999; Umbach \& Kuh, in press).

That structural diversity has a positive effect on student development and perceptions of the campus environment is not universally accepted. In their critique, Wood and Sherman (2001) identified three issues that raise questions about the relationship between structural diversity and learning to function in a diverse society. ${ }^{1}$ First, Wood and Sherman (2001) argue that multiple-regression results showing a positive relationship between informal interactional diversity and diversity outcomes demonstrate that structural diversity is not needed for students to learn to function in a diverse society. Their claim is based on the fact that effects in a multiple-regression model are statistically independent from other variables or effects in the model. Thus, they reason, a statistically significant relationship between interacting with diverse peers and learning to function in a diverse society is not necessarily a function of the diversity of the campus. In fairness, however, statistical independence does not mean that informal interactional diversity and/or diversity outcomes are unrelated to structural diversity. Structural diversity can be positively related to informal interactional diversity, which in turn is related to diversity outcomes, thereby producing a significant indirect relationship between the diversity of the student body and learning to function effectively in a diverse society.

Second, Wood and Sherman (2001) note that Gurin (1999) and others incorrectly equate statistical significance with educational importance. Wood and Sherman point out that the statistically significant relationships found in national studies are primarily a product of large sample sizes and do not necessarily accurately estimate the educational importance of these relationships. This concern about the effect of sample size on significance tests has prompted journal editors to require authors to report effect sizes

\footnotetext{
${ }^{1}$ Wood and Sherman (2001) also argue that there is not a direct relationship between structural diversity and diversity outcomes. Given that the present research focused on indirect relationships between structural diversity and the perceived campus environment that are mediated by informal interactional diversity, claims about the absence of a direct relationship are beyond the scope of this study.
} 
in addition to tests of statistical significance in manuscripts submitted for publication (Thompson, 1994).

The third objection raised by Wood and Sherman (2001) is definitional. They note that the rationale for affirmative action advanced by Justice Powell, as well as the justifications for diversity initiatives on many college campuses, presume that a diverse student body leads to interactions with peers who hold different views of the world, a category of interactions Wood and Sherman classify as "viewpoint diversity." They further argue that interacting with racially/ethnically diverse groups of students is not synonymous with interacting with groups of students who have diverse viewpoints, and conclude that research supporting current diversity initiatives must demonstrate that structural diversity leads to viewpoint diversity.

In addition to Wood and Sherman, other scholars have questioned whether interacting with diverse peers in college really influences the ability to function effectively in a diverse society. Bloom (1987) and D'Souza (1991) believe that interactions among diverse groups can lead to racial tension and a less hospitable, affirming campus environment. Observers who share this view worry that informal interactional diversity could well lead to undesirable outcomes.

Most advocates of diversity initiatives recognize that simply bringing students from historically underrepresented groups to campus does not automatically improve the campus climate for diversity or enhance learning opportunities (Hurtado, Milem, Clayton-Pedersen, \& Allen, 1999). The effects of informal interactions among diverse peers depend on the nature and quality of those interactions. Drawing on research from social psychology, Hurtado, Dey, Gurin, and Gurin (2003) concluded that interactions among diverse groups will have positive effects on outcomes when: (a) the groups are of equal status, (b) there are common goals and inter-group cooperation, (c) institutional leaders support group equality, and (d) there are extended opportunities for group members to get to know one another. Interactions between Black and White students at one institution resulted in an increasingly negative climate when the conditions identified by Hurtado and her colleagues were not present (Sampson, 1986). Adverse consequences of negative perceptions of the campus climate for diversity include lower levels of academic integration, institutional commitment, and academic achievement for both majority and minority students (Cabrera et al., 1999; Eimers \& Pike, 1997). Negative perceptions of the campus environment can also reduce the frequency of interactions between majority and minority students (Hurtado, Milem, Clayton-Pedersen, \& Allen, 1999).

Findings from other studies further complicate the nature of the relationships between structural diversity, informal interactional diversity, and the perceived campus environment. In a study of almost 100,000 students attending 349 four-year colleges and universities, Umbach and Kuh (in 
press) found that students attending liberal-arts colleges, many of them with relatively homogeneous student bodies, reported more experiences with diversity and greater gains in understanding diversity than students who attended much larger, and typically more diverse, institutions. In addition, the diversity experiences of students attending liberal arts institutions were generally unrelated to perceptions of the quality of relations among people on campus. The first finding seems to support the argument advanced by Wood and Sherman (2001) that structural diversity is not needed to achieve positive diversity outcomes. The second finding suggests that informal interactional diversity is unrelated to students' perceptions of the campus environment, or that the relationship may be contingent on institutional mission.

In a second study, Pike and Kuh (2005) examined data for 317 institutions participating in the 2001 National Survey of Student Engagement (NSSE). They found that at some institutions informal interactional diversity was positively related to the diversity of the student body, but negatively related to students' perceptions of the campus interpersonal environment and perceived institutional support for student success. To the extent that the tone of interactions among diverse groups influences openness to diversity, Pike and Kuh concluded that their results suggest that an increasingly diverse student body may reduce rather than improve openness to diversity. Most of the institutions with higher levels of informal interactional diversity and negative perceptions of the campus environment were large doctoral/research universities. They concluded that it was not possible to determine whether the negative perceptions of the campus environment were-as Bloom (1987) and D'Souza (1991) claimed - a direct result of interacting with diverse groups of students or a spurious correlation attributable to institutional characteristics such as size and types of mission, or a complex interaction between diversity initiatives and institutional characteristics.

Several factors may explain why the results reported by Umbach and Kuh (in press) and Pike and Kuh (2005) appear to contradict earlier studies. First, few of these earlier studies reviewed provided detailed descriptions of the range of diversity initiatives in place at participating institutions. Differences in findings may be the result of differences in the effectiveness of diversity initiatives. In addition, methodological differences in the studies may explain inconsistencies in the findings. For example, much of the previous research showing the positive effects of structural diversity relied extensively on data from the Cooperative Institutional Research Program (CIRP), while the two studies questioning the uniformly positive influence of structural diversity used data from the National Survey of Student Engagement (NSSE). It is not possible to assess the extent to which differences in the research results are attributable to differences in the measures used. However, attributing differences in diversity findings to differences between CIRP and NSSE is 
particularly troubling because it would suggest that unconditional support for affirmative action-oriented policies and programs may not generalize across contexts. It may also be the case that the definitions of structural diversity differed across some of the studies.

Another possible explanation for the apparently contradictory findings is design difference in the studies. The CIRP studies use longitudinal (i.e., freshman-senior) data, while the NSSE studies use cross-sectional designs. However, differences in research design at best represent a partial explanation of differences in the findings of CIRP and NSSE studies. The CIRP studies relied only on longitudinal data to represent student learning and other diversity outcomes. Relationships between structural diversity and interactions with peers were examined using data from the same point in time. Thus, different results for relationships between structural diversity and informal peer interactions across the studies cannot be attributed to differences between longitudinal and cross-sectional designs.

The third difference in the two sets of studies is the level of analysis and the extent to which institutional characteristics may have conditioned the results of the studies. In many of the studies supporting diversity initiatives, students were the unit of analysis while institutional characteristics were treated as elements of the college environment. As a result, these studies may not have paid sufficient attention to the influence of institutional characteristics on the effectiveness of diversity programs. There are also statistical explanations why student-level analyses could underestimate the effects of institutional characteristics. According to Ethington (1997), disaggregating institutional characteristics to the student level leads to misspecified standard errors for the effect coefficients in regression models. Misspecified standard errors, in turn, may mask statistically significant findings.

\section{Research Questions}

The Grutter v. Bollinger (2003) decision allowing selective colleges to continue using affirmative action to insure a critical mass of minority students has raised the stakes for the educational-value argument of structural diversity. That argument becomes the rationale for policies allowing institutions to admit students from underrepresented racial and ethnic backgrounds (Lane, 2003). Schools using this rationale are expected to empirically demonstrate the benefits of structural diversity. This study is designed to enhance understanding of the relationships between structural diversity and the campus environment as mediated by informal interactional diversity. Because some research (Pike \& Kuh, 2005, Umbach \& Kuh, in press) suggests that institutional characteristics may play an important role, our research included institutional characteristics as controls. Three questions guided the research: 
1. Is the perceived supportiveness of the campus environment related to informal interactional diversity, after taking institutional characteristics into account?

2. Is the perceived supportiveness of the campus environment related to the structural diversity of the student population, after taking institutional characteristics into account?

3. Is informal interactional diversity related to the structural diversity of the student population, after taking institutional characteristics into account?

Colleges and universities served as the units of analysis in our research because our focus was whether it is educationally defensible to use affirmative action or other initiatives to increase the structural diversity of a campus. We also sought to overcome two limitations of previous research identified by Wood and Sherman (2001). First, the analyses examined the educational importance of relationships as well as their statistical significance. Second, this study broadened the definition of informal interactional diversity to include interacting with students who hold different attitudes, beliefs, and values as well as interacting with students from different racial and/or ethnic backgrounds.

\section{ResearCh Methods}

\section{Conceptual Model}

Figure 1 shows the conceptual model used in this study. Consistent with prior research (Chang, 2001; Hu \& Kuh, 2003), the model assumes that the amount of interaction among diverse groups at an institution (i.e., informal interactional diversity) is related to the characteristics of the institution and the diversity of the student population. Institutional characteristics included in the model are institutional control, mission as represented by Carnegie classification, size, and urbanicity. ${ }^{2}$

Perceptions of the campus environment are a key element in the conceptual model. The term "campus environment" takes on a variety of meanings in higher education research. For this study, it means the extent to which students believe that their institutions are committed to their success and report that the social and working relationships among different groups on campus are positive (Indiana University Center for Postsecondary Research, 2004). Based on previous research, the conceptual model assumes that the perceived campus environment is directly related to institutional

${ }^{2}$ We originally included selectivity in the model as a general institutional characteristic. However, preliminary analyses indicated that an institution's selectivity was not uniquely related to informal interactional diversity, and we dropped it from the final model. 


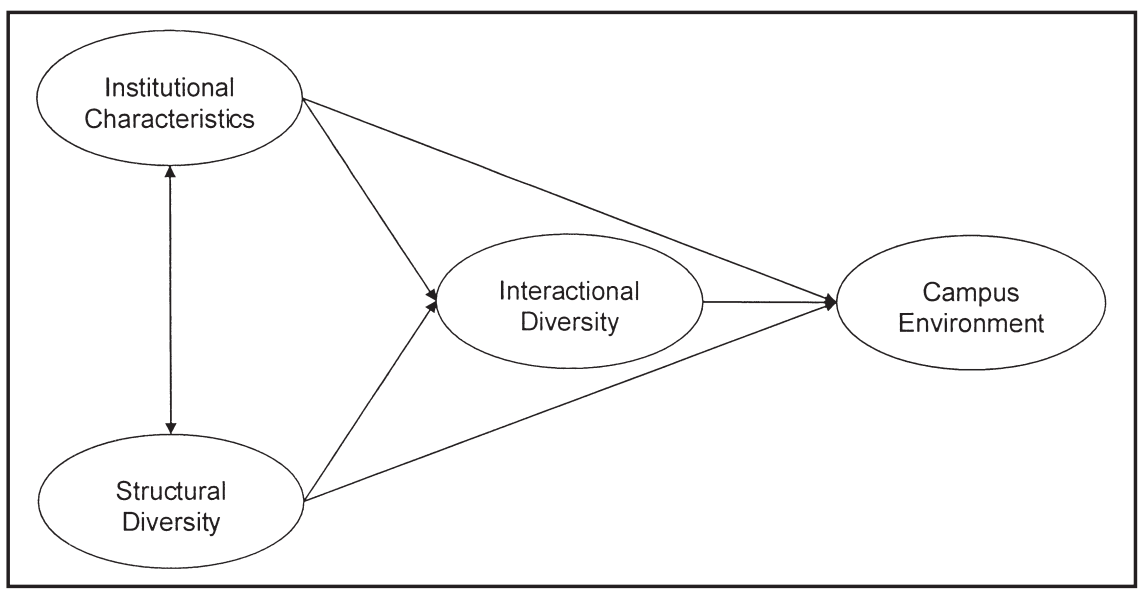

Figure 1. Conceptual model of the relationships among general institutional characteristics, structural diversity, informal interactional diversity, and the campus environment.

characteristics (Hurtado, 1992; Pascarella et al., 1996) and informal interactional diversity (Chang, 1999; Gurin, 1999; Umbach \& Kuh, in press). The model also assumes that the perceived campus environment is directly and indirectly related to structural diversity (Astin, 1993; Chang, 1999; Gurin, 1999). Finally, the model assumes that informal interactional diversity and structural diversity are related (Chang, 1999; Gurin, 1999; Hurtado, Dey, Gurin, \& Gurin, 2003). These assumed relationships correspond to the research question in the present study.

\section{Data Sources}

Institutions were the unit of analysis in this study. The institutional data came from the National Survey of Student Engagement (NSSE) Spring 2001 administration of The College Student Report and the Fall 2000 IPEDS institutional data collection. Information about informal interactional diversity and perceptions of the campus environment was drawn from seniors' responses to the NSSE survey. We used seniors' responses because we expected that the positive effects of structural and informal interactional diversity would be greater for students who had extended opportunities for interaction with diverse groups (Allport, 1954; Umbach \& Kuh, in press). Data about institutional characteristics and diversity of the student population come from the National Center for Education Statistics' Integrated Postsecondary Education Data System (IPEDS).

During the spring 2001 semester, approximately 45,000 seniors from 321 colleges and universities completed The College Student Report. Seniors at 
261 institutions had the option of responding either to a paper-and-pencil questionnaire or on the Internet. Sixty schools opted for web-only administration. About $69 \%$ of the senior respondents completed the paper version of the survey and $31 \%$ completed the web survey. Generally, administration mode did not affect the results, except that web respondents tend to report greater use of electronic technology (Carini et al., 2003). The overall average unadjusted institutional response rate for seniors was $41.8 \%$. Response rates ranged from $9.1 \%$ to $69.7 \%$. Table 1 displays the characteristics of senior respondents in comparison to the characteristics of all seniors at the participating institutions. The results presented in the table show that women, Caucasians, and full-time students tended to be overrepresented among the respondents. However, these differences were relatively small and should not affect the generalizability of the results for NSSE respondents.

Of the original 321 institutions participating in NSSE 2001, we excluded 16 due to low response rates, specialized missions, or missing IPEDS data. Table 2 displays the characteristics of the institutions included in the study and a national profile of four-year colleges and universities. On average, NSSE institutions tended to be slightly larger than the national profile. Public institutions, doctoral research universities, and liberal arts colleges were overrepresented while baccalaureate general colleges were underrepresented. Thus, the NSSE sample included a somewhat larger proportion of schools that educate the majority of undergraduates: large public colleges and universities. Participating schools were also similar to all four-year institutions in terms of urban/rural location. African American and Hispanic enrollment at NSSE institutions was slightly lower than the national average. Although the average proportion of minority enrollment was relatively low, the NSSE sample included several institutions with substantial minority enrollments. For example, 22 institutions (about 7\%) had minority enrollments of 50\% or greater, and 30 institutions (approximately 10\% had minority enrollments of $40 \%$ or greater. Almost one-quarter $(22.3 \%)$ of the institutions had minority enrollments of $25 \%$ or greater.

\section{Measures}

As previously noted, institutional means of seniors' responses to questions on the NSSE survey The College Student Report provided the measures of informal interactional diversity and the campus environment used in this research. The survey asks students about their perceptions of their college experiences and also asks them to indicate the frequency with which they engage in activities that represent good educational practice that are related to desirable learning outcomes (Kuh et al., 2001). Self-reported data are widely used in research on college effects, and their reliability and validity have been extensively studied. (See Baird, 1976; Berdie, 1971; Pace, 1985; 


\section{TABLE 1}

Characteristics of NSSE Senior Respondents and All Seniors at Participating Institutions

\begin{tabular}{lcc}
\hline & $\begin{array}{c}\text { NSSE Senior } \\
\text { Respondents }\end{array}$ & $\begin{array}{c}\text { All Seniors at } \\
\text { NSSE Schools }\end{array}$ \\
\hline Gender & & \\
Men & $35.4 \%$ & $41.9 \%$ \\
Women & $64.5 \%$ & $58.1 \%$ \\
Race/Ethnicity & & \\
African American/Black & $5.8 \%$ & $8.0 \%$ \\
American Indian/Alaska Native & $0.6 \%$ & $0.7 \%$ \\
Asian/Pacific Islander & $5.3 \%$ & $4.2 \%$ \\
Caucasian/White & $79.0 \%$ & $75.4 \%$ \\
Hispanic & $4.2 \%$ & $5.8 \%$ \\
Other & $0.2 \%$ & $2.9 \%$ \\
Multiple & $4.8 \%$ & $\mathrm{NA}$ \\
International & $4.0 \%$ & $3.0 \%$ \\
Enrollment Status & & \\
Full-time & $83.1 \%$ & $77.7 \%$ \\
Part-time & $16.9 \%$ & $22.3 \%$ \\
\end{tabular}

Pike, 1995; Pohlmann \& Beggs, 1974.) These studies show that self-report measures are likely to be valid under five conditions:

1. The information requested is known to the respondents.

2 . The questions are phrased clearly and unambiguously.

3. The questions refer to recent activities.

4. The respondents think the questions merit a serious and thoughtful response.

5. Answering the question does not threaten, embarrass, or violate the privacy of the respondent or encourage the respondent to respond in socially desirable ways (Kuh, 2001, p. 4).

Studies indicate that The College Student Report meets these five criteria and yields accurate, meaningful information about students' college experiences (Kuh et al., 2001).

We created two scales using nine survey questions. The first scale, informal interactional diversity, represented Wood and Sherman's concept of viewpoint diversity and was calculated using the responses to three questions:

- How often have you had serious conversations with students of a different race or ethnicity than your own? 


\section{TABLE 2}

\section{Characteristics of Institutions Participating in NSSE Compared to All Peer Institutions}

\begin{tabular}{lcc}
\hline & NSSE Institutions & All Peer Institutions \\
\hline Carnegie Classification & & \\
Doctoral research & $27.4 \%$ & $18.7 \%$ \\
Master's & $43.5 \%$ & $43.3 \%$ \\
Bac-liberal arts & $20.1 \%$ & $15.8 \%$ \\
Bac-general & $9.0 \%$ & $22.2 \%$ \\
Sector & & \\
Public four-year & $48.2 \%$ & $37.1 \%$ \\
Private four-year & $51.8 \%$ & $62.9 \%$ \\
Location & & \\
Large or mid-size city & $53.1 \%$ & $46.7 \%$ \\
Urban fringe & $21.7 \%$ & $24.8 \%$ \\
Large or small town & $20.1 \%$ & $20.8 \%$ \\
Rural & $5.0 \%$ & $7.8 \%$ \\
Race/Ethnicity & & \\
African American & & $12.0 \%$ \\
Asian American & $8.8 \%$ & $3.5 \%$ \\
Hispanic & $3.7 \%$ & $6.3 \%$ \\
Native American & $5.2 \%$ & $0.6 \%$ \\
White & $0.6 \%$ & $77.6 \%$ \\
FTE undergrad enrollment & $81.7 \%$ & 5,070 \\
& 7,037 & \\
\hline
\end{tabular}

- How often have you had serious conversations with students with religious beliefs, political opinions, or personal values very different from yours?

- To what extent does your institution emphasize encouraging contact among students from different economic, social, and racial or ethnic backgrounds?

Response options for the first two questions were "very often," "often," "sometimes," and "never." Response options for the final question were "very much," "quite a bit," "some," and "very little."

We calculated standardized scale scores using procedures developed by the NSSE staff (Indiana University Center for Postsecondary Research, 2004). Group mean generalizability analyses (Cronbach et al., 1972; Kane, Gillmore, \& Crooks, 1976; Pike, 1994; Pike, in press) revealed that dependable (i.e., Ep2 $\geq 0.70$ ) institutional scores could be calculated using as few as 50 respondents. 
The second scale used in the research was the NSSE Supportive Campus Environment benchmark. Here we derived scores from six survey questions. Three questions dealt with students' perceptions of the institution's emphasis on student success:

- To what extent does your institution emphasize providing the support you need to help you succeed academically?

- To what extent does your institution emphasize helping you cope with non-academic responsibilities (work, family, etc.)?

- To what extent does your institution emphasize providing the support you need to thrive socially?

Response options were "very much," "quite a bit," "some," and "very little." The remaining questions focused on students' relationships with other students, faculty members, and administrative personnel and offices. Responses were rated on seven-point semantic-differential scales. For relationships with students, the poles of the scale were "friendly," "supportive," and "sense of belonging," and "unfriendly," "unsupportive," and "sense of alienation." For relationships with faculty members, the extremes were "available," "helpful," and "sympathetic" and "unavailable," "unhelpful," and "unsympathetic." "Helpful," "considerate," and "flexible" and "unhelpful," "inconsiderate," and "rigid" served as the poles for the question about relationships with administrative personnel and offices. Once again, we used procedures recommended by the NSSE staff to calculate benchmark scores, and the group-mean generalizability coefficient for the benchmark was greater than 0.70 with 50 or more students.

IPEDS measures included institutional control (coded $1=$ public, $0=$ private) and Carnegie classification (dummy coded as doctoral/research universities, master's universities, liberal arts colleges, and baccalaureate general colleges [not coded]). An institution's locale was coded as urban (i.e., $\operatorname{urban}=1$, not urban $=0$ ) if the institution was located in a city or urban fringe area. Institutional size was represented by full-time equivalent (FTE) enrollment in thousands of students.

We used a modified version of Chang's (1999) diversity index as the measure of structural diversity. ${ }^{3}$ Chang (1999) reasoned that more traditional measures of diversity, such as the percentage of minority students at an institution, are flawed because relatively homogeneous minority-serving institutions would be considered racially diverse. His index, below, measures the variance in the student population across four racial/ethnic groups: African American (Black), Asian American (Asian), Caucasian (White), and

\footnotetext{
${ }^{3}$ The modified diversity index subtracted the deviation score from 1 , rather than calculating the reciprocal of the deviation score. The practical result of this modification was that all index scores in the present research ranged from 0 to 1 , with higher scores representing more heterogeneous student populations.
} 
Hispanic/Latino (Latino). The value for $u$ in the equation is the average of the percentages for the four ethnic groups. The index rewards heterogeneity in the student population. As a result, institutions with similar proportions of students across the four groups (e.g., 25\%, 25\%,30\%, and 20\%) have higher diversity-index scores than institutions with very homogeneous student populations (e.g., 5\%, 10\%, 80\%, 5\%).

\section{Data Analysis}

We analyzed data from the 305 institutions included in this study using the Lisrel 8.72 computer program (Jöreskog \& Sörbom, 2005). (See appendix

$$
1-\sqrt{\frac{(\% \text { Asian }-\mu)^{2}+(\% \text { Black }-\mu)^{2}+(\% \text { Hispanic }-\mu)^{2}+(\% \text { White }-\mu)^{2}}{4}}
$$

for the correlation matrix.) To evaluate the educational importance of the relationships among structural diversity, informal interactional diversity, and the perceived campus environment, we specified and tested five models. The first was a saturated model in which all possible relationships among institutional characteristics, structural and informal interactional diversity, and the perceived supportiveness of the campus environment were specified and allowed to vary. This model served as a baseline against which the other models could be evaluated.

In the second model, we removed from the model nonsignificant relationships between institutional characteristics and either measures of informal interactional diversity or the campus environment. The third model included the restrictions from the second model, plus the relationship between structural diversity and the campus environment was fixed to zero (i.e., removed from the model). In the fourth model, the relationship between informal interactional diversity and the perceived campus environment was fixed to zero, and the fifth model added the restriction that the relationship between structural diversity and informal interactional diversity was fixed to zero. Comparison of results across the final three models provided answers to the research questions in this study.

We performed goodness-of-fit tests to determine whether five models were statistically robust enough to answer the research questions. Chisquare statistics provided omnibus measures of fit and changes in chi-square provided indications of incremental goodness of fit. Assessing model fit using chi-square statistics alone is problematic because the statistics are influenced by sample size (Marsh, Balla, \& McDonald, 1988; Mulaik et al., 1989). Based on the recommendation of Hu and Bentler (1999), we also used a two-index test of model fit. The two indices used to assess model fit were the standardized root mean square residual (SRMR) and the comparative 
fit index (CFI). These indices are robust with respect to departures from multivariate normality and are insensitive to the effects of sample size (Hu \& Bentler, 1998, 1999). Based on their Monte Carlo analyses, Hu and Bentler (1999) recommended that values of SRMR $=0.080$ and CFI $\geq 0.95$ be used as criteria for selecting a suitable model.

Because the educational importance of relationships, as well as their statistical significance, was an issue in this study, we also used measures of explained variance (i.e., squared multiple correlations) to evaluate the appropriateness of the various models. A large decrease in the squared multiple correlation for an endogenous (i.e., outcome) variable indicated that eliminating the relationship between that variable and another variable was inappropriate because there was an educationally important relationship between the two variables.

\section{RESULTS}

Table 3 presents the goodness-of-fit results for the models in this study. Because all of the parameters in the saturated model were free to vary, the fit of the model was perfect. Moreover, the structural equations accounted for $39 \%$ of the variance in informal interactional diversity and $53 \%$ of the variance in the campus environment measure. Although the model fit was perfect, several institutional characteristics were not significantly related to the endogenous variables in the model:

1. Being a doctoral/research university or a master's university, as opposed to a baccalaureate general college, was not significantly related to informal interactional diversity.

2. Neither urbanicity nor size (i.e., FTE enrollment) was related to informal interactional diversity.

3. Being a liberal arts college, as opposed to a baccalaureate general college, was not significantly related to perceptions of a supportive campus environment.

Removing these relationships from the second model did not adversely affect goodness of fit. The small increase in the squared multiple correlation for the campus environment measure was likely a function of chance.

We eliminated from the third model the direct relationship between structural diversity and perceptions of a supportive campus environment, although structural diversity was still indirectly related to the campus environment measure through informal interactional diversity. Although this model produced statistically significant omnibus and incremental chi-square results, the standardized root mean square residual and comparative fit index values indicated that the model provided an acceptable representation of the data. Furthermore, eliminating the direct relationship between structural diversity and the campus environment measure did not appreciably influ- 


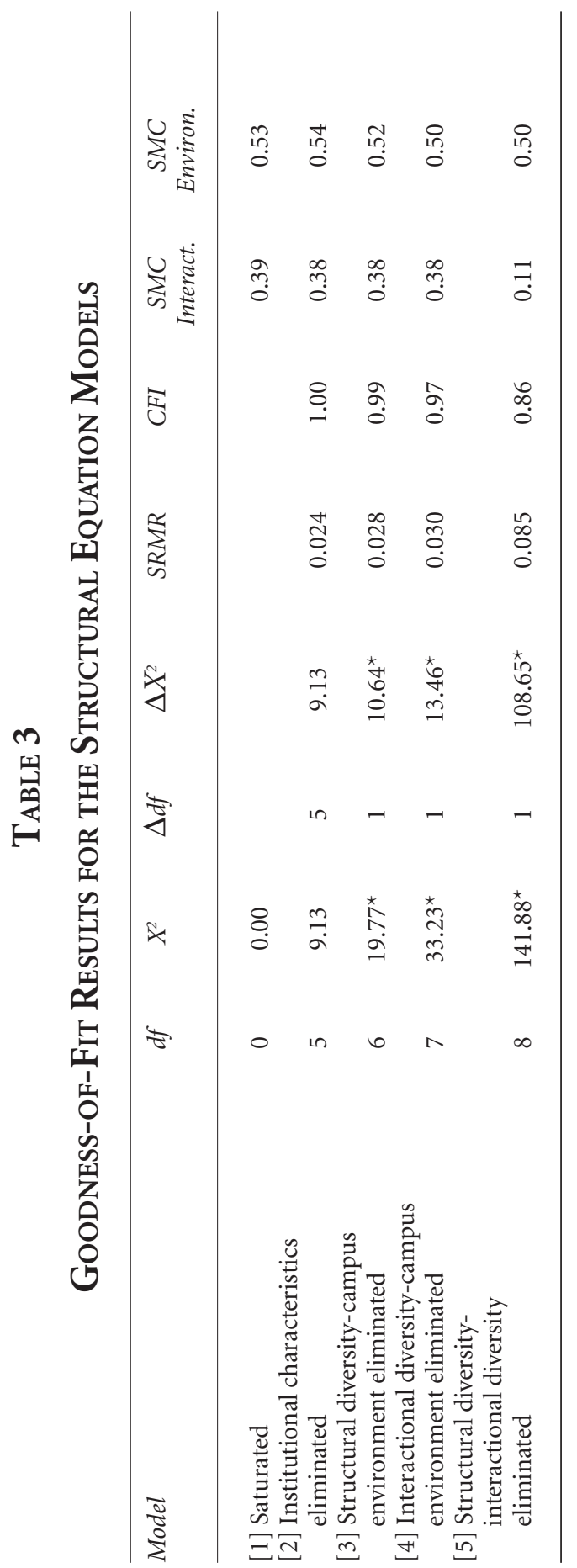


ence the squared multiple correlation for perceived supportiveness of the campus environment.

In the fourth model, we eliminated the relationship between informal interactional diversity and the perceived supportiveness of the campus environment. This modification also controlled for the indirect relationship between structural diversity and the campus environment measure and eliminated all indirect relationships between institutional characteristics and the supportiveness of the campus environment. Like the third model, the fourth model produced statistically significant omnibus and incremental chi-square results. The standardized root mean square residual and comparative fit index values again indicated that the model provided an acceptable representation of the observed data. Eliminating the relationship between informal interactional diversity and the supportive campus environment measure did not substantially reduce the squared multiple correlation for the campus environment measure.

In the final model, the relationship between structural diversity and informal interactional diversity was eliminated. This change produced a substantial increase in chi-square values, and both the standardized root mean square residual and the comparative fit index exceeded their threshold values for acceptable model fit. Moreover, the squared multiple correlation for informal interactional diversity declined substantially when we removed from the model the relationship between structural diversity and informal interactional diversity. Based on these findings, the fourth model was deemed to be the most parsimonious model that provided an acceptable representation of the data. As a consequence, we examined in detail the coefficients in the fourth model to determine the nature of the relationships among institutional characteristics, structural diversity, informal interactional diversity, and the perceived supportiveness of the campus environment.

Standardized coefficients from the fourth model appear in Table 4. All of these relationships were statistically significant. Informal interactional diversity was negatively related to being a public institution, but positively related to being a liberal arts college. There was a substantial positive relationship between structural diversity and informal interactional diversity. It is significant to note that all of the statistically significant relationships between institutional characteristics and perceived supportiveness of the campus environment were negative. Negatively related to the supportive campus environment measure were (a) being a public institution, (b) being a doctoral/research university, (c) being a master's university, and (d) being an urban institution. The relationship between FTE enrollment and the campus environment measure was also negative; that is, the larger the institution, the less supportive the campus environment. 


\section{TABLE 4}

Standardized Coefficients for the FinAL Structural Equation Model (Model 4)

\begin{tabular}{lcc}
\hline Variable & $\begin{array}{c}\text { Informal } \\
\text { Interactional } \\
\text { Diversity }\end{array}$ & $\begin{array}{c}\text { Perceived } \\
\text { Campus } \\
\text { Environment }\end{array}$ \\
\hline Public institution & $-0.21^{\star}$ & $-0.33^{*}$ \\
Doctoral/research university & 0.00 & $-0.47^{*}$ \\
Master's university & 0.00 & $-0.23^{*}$ \\
Liberal arts college & $0.29^{*}$ & 0.00 \\
Urban institution & 0.00 & $-0.15^{\star}$ \\
FTE enrollment (thousands) & 0.00 & $-0.12^{*}$ \\
Structural diversity & $0.52^{\star}$ & 0.00 \\
Informal interactional diversity & & 0.00 \\
Squared multiple correlation & 0.38 & 0.50 \\
* p $<0.05$ & & \\
\hline
\end{tabular}

\section{LIMITATIONS}

Although the results from the 2001 NSSE survey are generally consistent with the results from other NSSE administrations, this study analyzed only one year of data. If more institutions participating in other years were included, the results might differ in unknown ways. In addition, the relationships among general institutional characteristics, diversity measures, and campus environment measures were based on the responses of seniors. If a similar analysis was done using first-year students, the results might differ, inasmuch as they report more experiences with diversity compared with seniors (Kuh, 2003). Indeed, Umbach and Kuh (in press) found significant differences in the relationships between structural diversity and diversity outcomes for first-year students and seniors. Also, The College Student Report is a relatively short survey and, as a result, does not measure many relevant aspects of informal interactional diversity and the campus environment. Likewise, many likely outcomes of diversity initiatives were not studied. If additional questions were included on the survey, perhaps different results would emerge.

Information about the diversity initiatives at the institutions and whether the students responding to the survey participated in those initiatives was not available to us. However, such information could explain additional variance in diversity outcomes and could provide important insights into the results 
of this study. Because the institution served as the unit of analysis, aggregation bias in the results is a possibility (Burstein, 1980). At a minimum, the estimates of explained variance are greater than in many studies because student-level variance is not included in the models. Finally, the data used in this study are cross-sectional, not longitudinal. As a consequence, it is not possible to make causal claims about the effects of diversity initiatives on the college environment and student learning outcomes.

\section{DisCUSSION}

Despite these limitations, the results of this research have important implications for theory and practice. First and foremost, the results of this study indicate that a diverse student population is associated with higher levels of interaction among diverse groups of students. In fact, informal interactional diversity was more strongly related to structural diversity than any other institutional characteristic, although both institutional control and institutional mission were related to interactions among diverse groups. The strength of the relationship between structural diversity and informal interactional diversity also provides persuasive evidence that experiences with diversity are more likely to occur as the heterogeneity of the student population increases. Furthermore, structural diversity is influenced by more factors than interactions among different racial/ethnic groups. Structural diversity is associated with exposure to diverse viewpoints as well as diverse people.

The results of this research also indicate that the campus environment's perceived supportiveness is not related to the diversity of the student population on campus or the amount of interaction among diverse groups. It is important to understand that the results of this study do not indicate that interactions among diverse groups are unrelated to perceptions of the campus environment. The tone of the interactions among groups can have a substantial impact on the campus environment, and the tone of interactions was not examined in the present research. However, we did study the relationships between general institutional characteristics and the perceived campus environment. Those results indicated that such institutional characteristics as institutional control, institutional mission, and size are strongly related to the perceived campus environment.

Such organizations as the Association of American Colleges and Universities (Smith et al., 1997) and the Harvard Civil Rights Project (Orfield, 2001) have consistently argued that affirmative action in college admissions is needed to provide the conditions under which majority (i.e., White) students can interact with and learn about people who are different from themselves. It is believed that ultimately these interactions will result in a more affirming campus environment and help students learn to function effectively in 
a diverse society. This line of reasoning underlies Justice Powell's opinion in Regents of the University of California v. Bakke (1978) and affirmative action policies at the University of Michigan and elsewhere (see Gurin, 1999).

Our findings provide strong support for the first part of the affirmativeaction rationale, but not the second part. A diverse student population does appear to create the conditions in which students can and do interact with diverse groups of peers. This finding holds true even after controlling for a variety of general institutional characteristics. Counter to the rationale for affirmative action in admission policies, however, we found that a diverse student population was not associated with more positive perceptions of the campus environment. Nor was greater interaction among diverse groups associated with more positive perceptions of the campus environment.

Although our study provides only limited support for affirmative action in admissions, it does provide some unequivocal answers to critics of affirmative action policies. For example, Wood and Sherman (2001) argued that structural diversity has been linked to interactions among racially/ethnically diverse groups but not to interactions among groups with diverse viewpoints. Because of how we defined informal interactional diversity in this study, the results clearly show that structural diversity is positively related to viewpoint diversity. Relying on estimates of explained variance in the present research also answers a second issue raised by Wood and Sherman. The relationship between structural diversity and informal interactional diversity is both educationally meaningful and statistically significant. Our research also failed to confirm the claim made by Bloom (1987) and D'Souza (1991) that affirmative action policies and increased interaction among diverse groups lead to negative perceptions of the campus environment. Rather, our findings indicate that more frequent interaction between members of different groups had no effect on seniors' perceptions of the campus environment.

This study also corroborates the findings of Umbach and Kuh (in press) that students attending liberal arts colleges report higher levels of informal interactions with diverse peers than students attending other types of institutions, after accounting for structural diversity at those other types of institutions. Furthermore, in this regard, the advantage of liberal arts colleges is not a function of institutional control or size. At the same time, it is important to keep in mind that the items contributing to the informal interactional diversity scale encompass more than racial and ethnic diversity. Thus, it is possible that the higher levels of interaction with people from diverse groups at liberal arts institutions are due more to interactions with students who have different political, religious, and/or social views than to interactions with students from different racial/ethnic groups. Even so, it seems that students at liberal arts colleges have frequent experiences with diversity that are unrelated to the structural diversity of the campus. More research is needed to understand whether this phenomenon is due to certain 
peer effects, curricular offerings (such as more frequent use of course readings that feature forms of human diversity), and other college experiences, or even other factors.

Our findings also help clarify the results reported by Pike and Kuh (2005) who found evidence that informal interactional diversity was negatively related to perceptions of a supportive campus environment. They also noted that their results were likely confounded by institutional characteristics. The results of this research reveal that negative perceptions of the campus environment are associated with a variety of general institutional characteristics, including control, mission (i.e., Carnegie classification), size, and urbanicity.

In addition to lending additional support for diversity-friendly policies, our results tend to confirm the findings of more than three decades of research on college students (Pascarella \& Terenzini, 1991, 2005). Institutional characteristics and initiatives (e.g., structural diversity) can have direct and relatively powerful effects on students' behaviors (e.g., interactions with diverse peers). However, the effects of institutional initiatives on students' attitudes, perceptions of the campus environment and educational outcomes are mediated by a variety of factors that are frequently beyond the control of campus leaders. As a result, the effects of institutional initiatives on students' attitudes and learning outcomes are frequently indirect and relatively modest.

\section{Conclusion}

Numerous national organizations and scholars of American higher education advocate using affirmative action in admission decisions to increase the diversity of college campuses in the hopes of creating learning environments and providing experiences that will better prepare students to function effectively in a pluralistic society. This line of argument was a key element in the University of Michigan's defense of its affirmative action admission policies. The results of our study indicate that the diversity of an institution's student population is related to the frequency of interactions among students from different backgrounds. However, the results also indicate that a positive, affirming campus environment may not necessarily follow. The effects on the campus environment of interactions among diverse groups seem to depend on the nature and quality of the interactions, rather than on their quantity.

Thus, attracting diverse students should be seen as a necessary, but not sufficient, condition for positive diversity outcomes. Learning to function effectively in a diverse society also depends on the types of diversity experiences a student has and the commitment of institutional leaders to creating the conditions needed for positive and productive interactions among diverse groups of students, faculty, and staff. Future research should 
examine the relationships among structural diversity, informal interactional diversity, and perceived supportiveness of the campus environment using longitudinal data.

\section{APPENDIX}

\section{Correlations among the Variables in the Analyses}

\begin{tabular}{lrrrrrrrrr}
\hline & INTER & SUPEN & PUB & DOCT & MAST & LIBRT & URBN & FTE & DIVER \\
\hline INTER & 1.00 & & & & & & & & \\
SUPEN & 0.24 & 1.00 & & & & & & & \\
PUB & -0.23 & -0.50 & 1.00 & & & & & & \\
DOCT & 0.03 & -0.53 & 0.25 & 1.00 & & & & & \\
MAST & -0.25 & 0.02 & 0.11 & -0.54 & 1.00 & & & \\
LIBRT & 0.29 & 0.42 & -0.28 & -0.31 & -0.45 & 1.00 & & \\
URBN & 0.15 & -0.14 & -0.18 & 0.13 & -0.07 & -0.01 & 1.00 & & \\
FTE & -0.08 & -0.55 & 0.49 & 0.66 & -0.19 & -0.34 & 0.02 & 1.00 & \\
DIVER & 0.46 & -0.21 & 0.13 & 0.15 & -0.00 & -0.12 & 0.32 & 0.14 & 1.00 \\
& \\
INTER = Informal Interactional Diversity; SUPEN = Supportive Campus Environment; PUB = Public \\
Institution; DOCT = Doctoral/Research University; MAST = Master's University; LIBRT = Liberal Arts \\
College; URBN = Urban Institution; FTE = FTE Enrollment; DIVER = Structural Diversity
\end{tabular}

\section{REFERENCES}

Adams, S. E. (1995). The relationship between social contact and comfort with social interaction among student ethnic groups. NASPA Journal, 32, 251-261.

Antonio, A. L. (2001). The role of interracial interaction in the development of leadership skills and cultural knowledge and understanding. Research in Higher Education, 42, 593-617.

Allport, G. W. (1954). The nature of prejudice. Reading, MA: Addison-Wesley.

Association of American Colleges and Universities. (1995). American pluralism and the college curriculum: Higher education in a diverse democracy. Washington, DC: Author.

Astin, A. W. (1993). What matters in college? Four critical years revisited. San Francisco: Jossey-Bass.

Baird, L. L. (1976). Using self-reports to predict student performance. New York: College Board.

Berdie, R. (1971). Self-claimed and tested knowledge. Educational and Psychological Measurement, 31, 629-636.

Bikson, T. K., \& Law, S. A. (1994). Global preparedness and human resources. Santa Monica, CA: RAND Institute on Education and Training. 
Bloom, A. (1987). The closing of the American mind. New York: Simon and Schuster.

Bowen, W. G., \& Bok, D. (1998). The shape of the river: Long-term consequences of considering race in college and university admissions. Princeton, NJ: Princeton University Press.

Burstein, L. (1980). The analysis of multilevel data in educational research and evaluation. In D. C. Berliner (Ed.), Review of research in education (Vol. 8, pp. 158-233). Washington, DC: American Educational Research Association.

Cabrera, A. F., Nora, A., Terenzini, P. T., Pascarella, E. T., \& Hagedorn, L. S. (1999). Campus racial climate and the adjustment of students to college: A comparison between White students and African American students. Journal of Higher Education, 70, 134-160.

Carini, R. M., Hayek, J. H., Kuh, G. D., Kennedy, J. M., \& Ouimet, J. A. (2003). College student responses to web and paper surveys: Does mode matter? Research in Higher Education, 44, 1-19.

Carnevale, A. P., \& Fry, R. A. (2000). Crossing the great divide: Can we achieve equity when generation $Y$ goes to college? Princeton, NJ: Educational Testing Service.

Chang, M. J. (1999). Does racial diversity matter? The educational impact of a racially diverse undergraduate population. Journal of College Student Development, 40, 377-395.

Chang, M. J. (2000). Improving campus racial dynamics: A balancing act among competing interests. Review of Higher Education, 23, 153-175.

Chang, M. J. (2001). The positive educational effects of racial diversity on campus. In G. Orfield \& M. Kurlaender (Eds.), Diversity challenged: Evidence on the impact of affirmative action (pp. 175-186). Cambridge, MA: Harvard Education Publishing Group.

Chang, M. J. (2002). Preservation or transformation: Where's the real educational discourse on diversity? Review of Higher Education, 25, 125-140.

Chang, M. J., Astin, A. W., \& Kim, D. (2004). Cross-racial interaction among undergraduates: Some consequences, causes, and patterns. Research in Higher Education, 45, 529-553.

Chronicle of Higher Education. (2005, August 26). Almanac Issue, 2005-2006, p. 10.

Cortes, C. (1991). Pluribus \& unum: The quest for community amid diversity. Change, 23, 8-13.

Cronbach, L. J., Gleser, G. C., Nanda, H., \& Rajaratnam, N. (1972). The dependability of behavioral measurements: Theory of generalizability for scores and profiles. New York: Wiley.

D’Souza, D. (1991). Illiberal education. New York: Free Press.

Eimers, M. T., \& Pike, G. R. (1997). Minority and nonminority adjustment to college: Differences or similarities? Research in Higher Education, 38, 77-97.

Ethington, C. A. (1997). A hierarchical linear modeling approach to studying college effects. In J. C. Smart (Ed.), Higher education: Handbook of theory and research (Vol. 12, pp. 165-194). New York: Agathon. 
Flowers, L., \& Pascarella, E. T. (1999). Does college racial composition influence the openness to diversity of African American students? Journal of College Student Development, 40, 405-417.

Globetti, E. C., Globetti, G., Brown, C. L., \& Smith, R. E. (1993). Social interaction and multiculturalism. NASPA Journal, 30, 209-218.

Grutter v. Bollinger, 539 U.S. 306 (2003).

Gurin, P. Y. (1999). Expert report of Patricia Gurin, Gratz et al. v. Bollinger et al., No. 97-75321, Grutter et al. v. Bollinger et al. Retrieved May 3, 2004, from the University of Michigan Web site: http://www.umich.edu/ urel/admissions/ legal/expert/summ.html.

Henderson-King, D., \& Kaleta, A. (2000). Learning about social diversity: The undergraduate experience and intergroup tolerance. Journal of Higher Education, 71, 142-164.

Hu, L., \& Bentler, P. M. (1998). Fit indices in covariance structure modeling: Sensitivity to underparameterized model misspecification. Psychological Methods, 3, 424-453.

Hu, L., \& Bentler, P. M. (1999). Cutoff criteria for fit indexes in covariance structure analysis: Conventional criteria versus new alternatives. Structural Equation Modeling, 6, 1-55.

Hu, S., \& Kuh, G. D. (2003). Diversity experiences and college student learning and personal development. Journal of College Student Development, 44, 320-334.

Hurtado, S. (1992). The campus racial climate: Contexts for conflict. Journal of Higher Education, 63, 539-569.

Hurtado, S., Dey, E. L., Gurin, P.Y., \& Gurin, G. (2003). College environments, diversity, and student learning. In J. C. Smart (Ed.), Higher education: Handbook of theory and research (Vol. 18, pp. 145-189). Dordrecht, Netherlands: Kluwer.

Hurtado, S., Milem, J. F., Clayton-Pedersen, A. R., \& Allen, W. (1998). Enhancing campus climates for racial/ethnic diversity: Educational policy and practice. Review of Higher Education, 21, 279-302.

Hurtado, S., Milem, J. F., Clayton-Pedersen, A. R., \& Allen, W. (1999). Enacting diverse learning environments: Improving the climate for racial/ethnic diversity in higher education (ASHE-ERIC Higher Education Report Volume 26, No. 8). Washington, DC: George Washington University.

Hurtado, S., \& Wathington Cade, H. (1999, November). Intragroup and intergroup dynamics on campus: Understanding interaction across racial/ethnic communities. Paper presented at the annual meeting of the Association for the Study of Higher Education, San Antonio, TX.

Indiana University Center for Postsecondary Research. (2004). NSSE institutional report 2004. Bloomington: Indiana University.

Jöreskog, K. G., \& Sörbom, D. Lisrel 8.72. Chicago: Scientific Software International.

Kane, M. T., Gillmore, G. M., \& Crooks, T. J. (1976). Student evaluations of teaching: The generalizability of class means. Journal of Educational Measurement, 13, 171-183. 
Knefelkamp, L. (1998, April). Diversity and education in a democratic society. Presentation at the American Commitments meeting of the Association of American Colleges and Universities, Ann Arbor, MI.

Kuh, G. D. (2001). The National Survey of Student Engagement: Conceptual framework and overview of psychometric properties. Bloomington: Indiana University Center for Postsecondary Research.

Kuh, G. D. (2003). What we're learning about student engagement from NSSE. Change, 35(2), 24-32.

Kuh, G. D., Hayek, J. C., Carini, R. M., Ouimet, J. A., Gonyea, R. M., \& Kennedy, J. (2001). NSSE technical and norms report. Bloomington: Indiana University Center for Postsecondary Research and Planning.

Lane, C. (2003, June 24). Affirmative action for diversity upheld in 5 to 4 vote: Justices approve U. Mich. Law School Plan. Washington Post, p. A1.

Loo, C. M., \& Rolison, G. (1986). Alienation of ethnic minority students at a predominantly White institution. Journal of Higher Education, 57, 58-77.

Marsh, H. W., Balla, J. R., \& McDonald, R. P. (1988). Goodness-of-fit indices in confirmatory factor analysis: The effect of sample size. Psychological Bulletin, 103, 391-410.

Mulaik, S. A., James, L. R., Van Alstine, J., Bennett, N., Lind, S., \& Stidwell, C. D. (1989). Evaluation of goodness-of-fit indices for structural equation models. Psychological Bulletin, 105, 430-445.

Orfield, G. (2001). Introduction. In G. Orfield \& M. Kurlaender (Eds.), Diversity challenged: Evidence on the impact of affirmative action (pp. 1-30). Cambridge, MA: Harvard Education Publishing Group.

Pace, C. R. (1985). The credibility of student self-reports. Los Angeles: Center for the Study of Evaluation, University of California Los Angeles.

Palmer, S. R. (2001). A policy framework for reconceptualizing the legal debate concerning affirmative action in higher education. In G. Orfield \& M. Kurlaender (Eds.), Diversity challenged: Evidence on the impact of affirmative action (pp. 49-80). Cambridge, MA: Harvard Education Publishing Group.

Pascarella, E. T., Edison, M., Nora, A., Hagedorn, L. S., \& Terenzini, P. T. (1996). Influences on students' openness to diversity and challenge in the first year of college. Journal of Higher Education, 67, 174-195.

Pascarella, E. T., Palmer, B., Moye, M., \& Pierson, C. T. (2001). Do diversity experiences influence the development of critical thinking? Journal of College Student Development, 42, 257-271.

Pascarella, E. T., \& Terenzini, P. T. (1991) How college affects students: Findings and insights from twenty years of research. San Francisco: Jossey-Bass.

Pascarella, E. T., \& Terenzini, P. T. (2005). How college affects students: A third decade of research (Vol. 2). San Francisco: Jossey-Bass.

Pike, G. R. (1994). Applications of generalizability theory in higher education assessment research. In J. C. Smart (Ed.), Higher education: Handbook of theory and research (Vol. 10, pp. 45-87). New York: Agathon.

Pike, G. R. (1995). The relationship between self reports of college experiences and achievement test scores. Research in Higher Education, 36, 1-21. 
Pike, G. R. (2002). The differential effects of on- and off-campus living arrangements on students' openness to diversity. NASPA Journal, 39, 283-299.

Pike, G. R. (in press). The generalizability of NSSE scalelets for college- and department-level assessment. Research in Higher Education.

Pike, G. R., \& Kuh, G. D. (2005). A typology of student engagement for American colleges and universities. Research in Higher Education, 46, 185-210.

Pohlmann, J., \& Beggs, D. (1974). A study of the validity of self-reported measures of academic growth. Journal of Educational Measurement, 11, 115-119.

Regents of the University of California v. Bakke, 438 U.S. 265 (1978).

Rudenstine, N. L. (2001). Student diversity and higher learning. In G. Orfield \& M. Kurlaender (Eds.), Diversity challenged: Evidence of the impact of affirmative action (pp. 31-48). Cambridge, MA: Harvard Education Publishing Group.

Sampson, W. A. (1986). Desegregation and racial tolerance in academia. Journal of Negro Education, 55, 171-184.

Smith, D. G., Gerbick, G. L., Figueroa, M. A., Watkins, G. H., Levitan, T., Moore, L. C., Merchant, P. A., Beliak, H. D., \& Figueroa, B. (1997). Diversity works: The emerging picture of how students benefit. Washington, DC: American Association of Colleges and Universities.

Sweezy v. New Hampshire, 354 U.S. 234 (1957).

Taylor, S. H. (1998). The impact of college on the development of tolerance. NASPA Journal, 35, 281-295.

Terenzini, P. T., Cabrera, A. F., Colbeck, C. L., Bjorklund, S. A., \& Parente, J. M. (2001). Racial and ethnic diversity in the classroom: Does it promote student learning? Journal of Higher Education, 72, 509-531.

Thompson, B. (1994). Guidelines for authors. Educational and Psychological Measurement, 54, 837-847.

Umbach, P. D., \& Kuh, G. D. (in press). Student experiences with diversity at liberal arts colleges: Another claim for distinctiveness. Journal of Higher Education.

Whitt, E. J., Edison, M. I., Pascarella, E. T., Terenzini, P. T., \& Nora, A. (2001). Influences on students' openness to diversity and challenge in the second and third years of college. Journal of Higher Education, 72, 172-204.

Wood, T. E., \& Sherman, M. J. (2001, April). Is campus racial diversity correlated with educational benefits? In Race and higher education: Why Justice Powell's diversity rationale for racial preferences in higher education must be rejected (Part IV). Retrieved July 15, 2005, from http://www.nas.org. 